\title{
E-commerce and Entrepreneurship in SMEs: Case of myBot
}

\begin{tabular}{|r|l|}
\hline Journal: & Journal of Small Business and Enterprise Development \\
\hline Manuscript ID & JSBED-03-2017-0088.R3 \\
\hline Manuscript Type: & Research Paper \\
\hline Keywords: & $\begin{array}{l}\text { E-commerce, Entrepreneurship, SMEs, Contextualism, Interpretive, Case } \\
\text { Study, SMN }\end{array}$ \\
\hline \multicolumn{2}{|c}{} \\
\hline
\end{tabular}

SCHOLARONE ${ }^{m}$

Manuscripts 


\section{Abstract}

Purpose: The adoption of e-commerce in Small and Medium enterprises (SMEs) is a much researched topic in developed and developing nations. The application of mobile devices, and social media networks (SMN) such as Facebook has revolutionalised the e-commerce adoption process in SMEs. However, research into this area is still developing and there is a dearth of knowledge on how SMEs in developing countries enact and apply this phenomenon. This paper explains how e-commerce entrepreneurship using SMN is conceptualised and applied in SMEs, and highlights factors that influence this e-commerce innovation.

Design/Methodology/Approach: An interpretive and qualitative case study approach was adopted as a methodological foundation in a firm pseudo-named, myBot. The study employed Contextualism theory as a meta-theoretical framework to conceptualise and analyse the e-commerce entrepreneurship process in the firm. The study employed face-toface semi-structured and unstructured interviews with the manager as primary means of obtaining in-depth information. Further information was obtained through website content analysis and document analysis of the firm's reports and observations.

Findings: The results unearth a socially-constructed feature of e-commerce entrepreneurship that draws from myBot's manager's innovative ability to use Facebook and e-mail to increase sales through its niche market. Factors that propelled e-commerce entrepreneurial activities using Facebook include trust, commitment and innovativeness.

Originality/Value: The study provides a theoretical lens into the understanding of an ecommerce entrepreneurship process using a Contextualism theory. The paper showcases how e-commerce using Facebook can be portrayed in a developing country context.

Keywords: E-commerce, Entrepreneurship, SMN, Contextualism, SMEs, Interpretive, Case study.

Article Classification: Research Paper

\section{Introduction}

\subsection{Definitions and Rationale}

Small and Medium Enterprises (SMEs) are a significant component of many economies in the world (Ahmedova, 2015; Alyoubi, 2015; Dahnil, et al., 2014). This is because of the contribution they make in creating employment and facilitating regional development and innovation (Jones \& Beynon-Davies, 2011), thus impacting positively on the economic status of their countries (Ghobakhloo, et al., 2011). Electronic commerce (e-commerce), which is described as the buying and selling of goods and products, services and funds through computer networks, especially the Internet (Turban et al., 2008, p.8) has taken centre stage in recent times. Additionally, the definition of e-commerce does encompass other telecommunications networks such as wireless Internet as adopted in Marcelo, et al. (2014). E-commerce has been viewed as a catalyst and an innovation that can enhance SMEs entrepreneurial characteristics in developed and developing countries (Alyoubi, 2015; 
Kurnia, et al., 2015). E-commerce activities have usually been categorized as business to business (B2B) when business organisations engage with business, and business to consumer (B2C), when businesses engage with consumers (Turban, et al., 2008). These definitions will lay the foundation for discussion in this study.

Social media networks (SMN) such as facebook, whatsapp, twitter, skype, and other similar technologies have assisted to redefine e-commerce due to their mobility features and the versatility of mobile devices. The term mobile commerce, or m-commerce has been defined when products and services are transacted online (Hajli, 2015), and when the emphasis leans on the social activity, the phenomenon has been defined as social commerce or s-commerce. Researchers (Liebana-Cabanillas \& Alonso-Dos-Santos, 2017; Hajli, 2015) treat s-commerce as a subset of e-commerce, thus this study draws from this definition. Bocconcelli, et al.(2017) argue that SMN can be a significance resource for improving the SMEs sales process. Other than using SMN for communication, organisations use them to create new markets, innovate, and achieve efficiency (Marcelo, et al., 2014). They further argue that e-commerce has been conceived as evolutionary and is a key strategy for reaching global markets for SMEs (Marcelo, et al., 2014).

E-commerce adoption in SMEs has attracted research in developed countries (e.g. Liebana-Cabanillas \& Alonso-Dos-Santos, 2017; Grant, et al., 2014; Scupola, 2009; Pickernell, et al., 2013) as well as developing countries (Kabanda \& Brown, 2017; Al-Bakri \& Katsioloudes, 2015; Kurnia, et al., 2015; Shemi \& Procter, 2013; Zaeid, 2012; Olatokun \& Kebonye, 2010; Molla \& Licker, 2005), just to name a few. Although several studies have been undertaken and have informed current practice in certain directions, most research has explained e-commerce behavior based on the technology aspects of e-commerce adoption (Kurnia, et al., 2015), neglecting other important aspects such as the social-cultural issues that encompass social media networks (SMN).

This study draws from previous studies by Avgerou $(2013,2001)$ and others (Shemi \& Procter, 2013; Zaeid, 2012; Walsham, 2006) who argued that context is very significant in understanding the development of informations systems in organisations, as such, any studies on e-commerce adoption in SMEs must fully embrace all such characteristics. Thus, we follow a social-technical approach that aligns with the nature of e-commerce entrepreneurship process in SMEs in a developing country context. A theoretical aspect of context has been employed through Pettigrew's (1990, 1997) Contextualism theory. Furthermore, the philosophies of conceptualising and researching e-commerce using SMN have also been varied, with the majority of studies pursuing positivist studies with an 
objective approach (Kabanda \& Brown, 2017). The summarised reporting of e-commerce activities in previous studies is problematic (Shemi \& Procter, 2013) as it ignores the divergent characteristic of SMEs and the different ways of appreciating the e-commerce adoption process (Lefebvre, et al., 2005). Some of the findings are conflicting (Tan, et al., 2009) whilst others fail to address the complexity of e-commerce (Kurnia, et al., 2015) and its changing nature affected by SMN organisation. The contextual aspects that embrace the social impact of e-commerce adoption in SMEs pose knowledge gaps that require further investigation to obtain a complete and wholistic understanding of SME e-commerce adoption process in developing country contexts. SMEs are generally known to be resourceconstrained in terms of finance (Woschke, et al., 2017) and skilled manpower. Thus they should concentrate on growing their business in terms of incremental innovation rather than radical innovation (Woschke, et al., 2017).

Whilst noting that SMEs are unique, resource-constrained (Woschke, et al., 2017) and thus have different and varied experiences of e-commerce adoption (Parker \& Castleman, 2009), most studies claiming to tackle the SME challenges have been narrow-minded and lacked clear sense of direction (Sin, et al., 2016). Popular theories in previous studies such as the Theory of Planned Behaviour (TPB), the Technology Acceptance Model (TAM) and its various extensions, the Technology-Organisation-Environment (TOE) framework, the Perceived E-readiness Model (PERM), and the Diffusion of Innovation Theory (DIT) have generally lacked a social-cultural emphasis that is grounded in the nature and characteristics of SMEs. In order to detangle the complexities of e-commerce process in SMEs, this study employs a qualitative and interpretive case approach to unearth details of e-commerce entrepreneurship by drawing from Contextualism theory proposed by Pettigrew (1990). Calls have been made for more qualitative studies (Zaeid, 2012) to explain social aspects of SME adoption of e-commerce (Kabanda \& Brown, 2017) especially with SMN.

An interpretive approach was adopted to investigate the development of e-commerce in an SME, pseudo-named myBot, in Botswana. The study aimed to depict the natural environment in which myBot exists in a developing country context of Botswana; how the firm started, and how it grapples with pertinent issues regarding the acquisition of Ecommerce tools, the decisions that managers make in favour of, or against e-commerce, and the conflicting situations they face amidst the complex business environment. This study reports on how one small firm extended their access to global markets by taking advantage of the inexpensive SMN such as Facebook. The research questions in this study are stated as follows: i) How do SMEs incorporate social media networks to develop e-commerce 
adoption and entrepreneurship? ii) What factors influence e-commerce adoption using social media networks?

In order to answer the above questions, the study draws from Pettigrew's Contextualism theory (1990) to formulate a framework for understanding the conceptualisation, development and e-commerce entrepreneurship using SMN in a Botswana small firm. Three interrelated and interconnected components namely, content, context and process are drawn (Karyda, et al, 2005; Pettigrew, 1997) to explain the engaging process of e-commerce and how the firm's decision process is shaped to realise an e-commerce feature defined through the application of Facebook.

Firstly a background of Botswana is given in the next section.

\subsection{Botswana Background}

Botswana is a landlocked country, with a population slightly above 2 million. It boasts one of the stronger economies in Africa that heavily depends on the mining industry. Botswana has an economy that embraces and nurtures the activities of SMEs. The government of Botswana (GoB) is the largest consumer of Information and Communication Technologies (ICTs) as well as the largest employer in the country, presiding over major business undertakings with the private sector.

The term ICT has been defined in various ways by authors but the following shall be adopted from Moursund (2005). ICT combines a 'full range of computer hardware and software, telecommunication and cell phones, the Internet and Web, wired and wireless networks, digital still and video cameras, robotics, and so on.' (Moursund, 2005, p. 4 ). The GoB has been looking for strategies to diversify the economy from the dominance of two sectors; mining and government (Shemi \& Procter, 2013; MCST, 2007), by encouraging the participation of SMEs from various industries and sectors (MCST, 2007). Internet usage has been slow over the years but there has been a surge after 2009, as Table I from the International Telecommunications Union (ITU) and Internet World Statistics (IWS) shows the following:

Table I $<<$ insert here $>>$ 


\section{Table I: Botswana Internet Statistics}

Access to ICTs has tremendously improved with mobile phones being used by more than $50 \%$ among individuals who access the Internet. The application of ICT and electronic commerce (e-commerce) in SMEs is a crucial area whose positive impact can add social and economic value to Botswana. Botswana's national ICT policy (MCST, 2007) provides guidance on the application and significance of e-commerce in the country. E-commerce issues and concerns as given in the Botswana's National ICT policy document acknowledge the disparities in the distribution of ICT products and services in the country, commonly known as the domestic digital divide (Shemi, 2013). The urban cities are relatively wellsupplied with radio, television, telephone and Internet services whereas the remote and rural regions are in dire need of these facilities. Within corporate entities, the general e-readiness status is comparatively higher than in individual homes, as has been shown in the Global information technology report (GITR) (Baller, et al., 2016). The national ICT policy, which was officially published by the government of Botswana in 2007, also shows a relatively low numbers of skilled ICT personnel in the country and is still being reflected in recent statistics. Based on the Networked Readiness Index (NRI) (Baller, et al., 2016) tool which is used to assess a country's preparedness to reap the benefits of emerging technologies and capitalize on the opportunities presented by the digital transformation era and beyond, Botswana has been ranked 101 out of 143 countries that participated in the analysis (Baller, et al., 2016). This is a lower ranking for a country like Botswana as other countries such as Rwanda $\left(80^{\text {th }}\right)$ and Kenya $\left(89^{\text {th }}\right)$ have surpassed it in the capitalization of ICT for digital transformation.

Within the private sector, a few multinational organisations exist that provide professional ICT services to the government of Botswana (GOB) and other public institutions. Previous studies (Olatokun \& Kebonye, 2010 ; Uzoka et al., 2007) to ascertain e-commerce adoption in Botswana reported a limited application of e-commerce in small and medium firms. Key 
challenges were poor or slow Internet, concerns about security and privacy, lack of ecommerce infrastructure, lack of IT knowledge among SME managers.

In the context of Botswana, the definition of small and medium enterprise (SME) is one that employs 1 to 49 persons and has an annual turnover of up to US dollar \$130,000 (with a balance sheet of $\$ 5,000$ per month) (Botswana Ministry of Commerce and Industry, 1999) with an international rate of conversion of 1 US dollar being approximately equivalent to BWP 10 (Botswana Pula).

The organisation of this paper is as follows: a review of related literature on e-commerce adoption and entrepreneurship, the application of social media networks and previous theories of e-commerce adoption are presented after this section of Introduction. This is followed by a discussion on the research framework using Contextualism theory. Section 3 presents the research methodology, followed by the results and interpretation of the findings in Section 4. The discussion of findings is presented in Section 5, and Section 6 presents the conclusion, some key highlights, and implications of findings.

\section{Literature Review}

\subsection{E-commerce Adoption and Entrepreneurship in SMEs}

Researchers have argued that "E-commerce is a strategy for growth especially by SMEs" (Grandon, et al., 2011), assisting them to compete with large firms by gaining new customers in global markets (Marcelo, et al., 2014). Electronic commerce systems can be categorised into two parts: the simplest level which covers the promotion and advertising of products and services, and electronic distribution of goods, and the second and advanced level which includes payment and distribution at local and global levels (Al-Bakri \& Katsioloudes, 2015). Although e-commerce benefits have been observed at country levels such as in China, USA, Brazil (Alyoubi, 2015), Australia, Denmark, Canada, Malaysia, Sweden, Portugal, just to name a few, its benefits have not trickled down to the majority of businesses (Savrul, et al., 2014; Molla \& Heeks, 2007).

Early studies in e-commerce adoption suggested that organisations undergo stages of growth in their adoption of ICT and e-commerce technology in a linear fashion, from one stage to a higher level, in a well-planned, sequential process (Daniel, 2003; Taylor \& Murphy, 2004). A common feature in these early studies was an inclination towards technology aspects of e-commerce adoption process. Some researchers categorised ecommerce development activities into two: initial adoption and later institutionalisation stages (Grandon, et al., 2011; Kapurubandara, 2009; Tan, et al., 2007; Mollar and Licker, 
2005). In the manufacturing sector of Canadian SMEs, Lefebvre et al., (2005) undertook a study aimed at capturing the gradual enfolding of B2B e-commerce in SMEs. They found a logical evolutionary path in the penetration of e-commerce. Their findings point to a realisation of more benefits from e-commerce than first conceived. It was also noted that SMEs had tried innovative and entrepreneurial ways and were eager to improve their business operations using the websites (Lefebvre et al., 2005). Common e-commerce activities in early studies were e-mail and the Internet, with limited application of websites.

Early models faced criticism that they were too simplistic and the linear progression they proposed could not capture the complex nature of small-firm activities (Kabanda \& Brown, 2017; Parker \& Castleman, 2009). Furthermore, early e-commerce studies in SMEs put more focus on technology aspects (Kabanda \& Brown, 2017), with the assistance of theories such as the Technology Acceptance Models (TAM) and its derivatives, and other similar theories such as the Theory of Planned Behaviour (TPB). Previous studies were unable to account for unexpected changes in the development of e-commerce in the organisations and could not fully account for why some SMEs thrived in some regions and others did not.

Previous studies have noted that SMEs in developing countries are generally slow in developing e-commerce (Kabanda \& Brown, 2017; Kabongo \& Okpara, 2014; Zaeid, 2012 ) as compared to those in developed regions of the world (Rahayu \& Day, 2015; Shemi, 2013). With respect to Asian countries, Jahanshahi, et al.(2013) undertook a study in India, Malaysia and Iran to ascertain e-commerce benefits achieved by SMEs. They found that 'an enhanced company brand and corporate image' are an e-commerce advantage and 'security and privacy' are key concerns. Their findings on security concerns corroborate previous findings by Olatokun \& Kebonye (2010) in Botswana, and Zaied (2012) in Egypt. A survey study on 292 Indonesian SMEs by Rahayu \& Day (2015) found that perceived benefits, technology readiness, owners' innovativeness, owners' information technology (IT) ability and owners' IT experience are the determinant factors influencing Indonesian SMEs to adopt e-commerce.

E-commerce has been dubbed a complex phenomenon (Alyoubi, 2015) and a socialtechnical endeavour in SMEs (Sarosa, 2012). As new trends in ICTs are being developed, the application of e-commerce in SMEs needs to transform to comform to new standards of business, and systems of operations. This in turn generates interest to understand how ecommerce adoption evolves in organisations, how SMEs conceptualise the transformation of e-commerce using SMN, and the philosophies they employ, and how the actors of change incorporate SMN to improve the e-commerce process. Researchers have defined entrepreneurship with a focus on the originator and owner of the business (Eijdenberg et al., 
2015), who sometimes goes further to be a 'risk-taker' after taking steps to create a small business. This study aligns with the understanding of e-commerce as an entrepreneurship and undertakes to investigate the entrepreneurial traits of key managers that introduce an innovation using SMN.

Studies on entrepreneurship and small businesses have been lacking in developing countries (Eijdenberg et al., 2015). In a study on least developed countries (LDC) in Rwanda, Eijdenberg, et al.(2015) investigated the relationship between entrepreneurial traits and small business growth; they concluded that 'entrepreneurial motivation is not a clear distinction between necessity and opportunity, but that a mix of motivations is important to assess the growth of small businesses in an LDC' (p. 212). The study by Kabongo \& Okpara (2014) on Information Technology (IT) possession among Congolese SMEs provides similarity to the analysis of e-commerce adoption and entrepreneurship in this study. IT possession can be considered a proxy for e-commerce adoption in SMEs. However, it was not clearly mentioned for what purpose the Congolese SME's were using IT. It was found that the Telecommunications sector had the highest usage amongst the SMEs (Kabongo and Okpara, 2014).

Ghobakhloo \& Tang (2013) studied the role of owner managers in the adoption of ecommerce among SMEs. Perceived benefits, perceived compatibility, perceived risks, perceived costs, and innovativeness were found to be the significant determinants of decisions to adopt e-commerce (Ghobakhloo \& Tang, 2013) aligning with earlier studies by Ghobakhloo et al. (2011). In Portugal, Cragg, et al. (2011) found that a low level of organisational readiness slowed the development of e-commerce among SMEs. The study by Awa, et al.(2015) shows that SMEs in Nigeria are yet to exploit the full potential of ecommerce solutions. The study also reports several challenges such as non-transparency in government support programs, location factors, weak finances, firm's size, confidentiality of information, infrastructural inadequacy and lack of openness and business integration. In a Turkish study to determine the potential of e-commerce in a globalized business environment, Savrula, et al (2014) identified internal and external factors that affect SMEs. The internal organizational factors were SMEs e-commerce strategy and the perceptions and experience of managers. The external factors were the readiness of local and global trading partners (TPs), and the external pressure by local and global TPs to adopt e-commerce systems, including the infrastructure, network availability and online transactions.

In summary, the initial e-commerce adoption in SMEs has the following inhibiting challenges: lack of technology, cost, cultural values, lack of management enthusiasm, 
security, privacy concerns (Mohammed \& Tejay, 2017; Olatokun \& Kebonye, 2010), and lack of credit finance (Awa, et al., 2015).

The advanced level of e-commerce growth in SMEs features the application of websites for interaction with consumers in the local and global markets for making online payments. In Malaysia, Ramayah, et al. (2016) studied the intention of SMEs to continue to employ websites for advanced operations. They found critical determinants were Chief Executive Officer's (CEO) innovativeness, CEO's IT attitude, relative advantage, and cost. These findings are similar to those of Olatokun \& Kebonye (2010). In Thailand, Ueasangkomsate (2015) lamented the lack of capitalisation in export business in SMEs whereas, Pickernell, et al.(2013) found varied experiences of e-commerce trading ability in UK SMEs. Ramayah, et al.(2016) have noted that website utilisation has been challenging generally and scanty successes have been noted in developed and developing countries alike.

Avgerou \& Boyi (2013) explain the emergence of networks of micro-entrepreneurs that conduct business on a Web platform known as Taobao in China. They demonstrate 'two case studies of networks that show how Web platform tools and services create conditions of possibility for developing online business by micro-entrepreneurs and for overcoming cultural reluctance of economic exchange with strangers'( p. 329). They further claim that 'economic activity on Web platforms is embedded in a mix of virtual and community-based relations that are shaped by and alter the behavioural norms of a local culture' (Avgerou \& Boyi, 2013). This study exemplifies some interaction of web technology and SMN in the SME to improve and advance the e-commerce process in a Botswana context.

\subsection{Social Media Networks (SMN) and E-commerce Adoption in SMEs}

The application of social media networks (SMN) such as facebook, twitter, whatsapp, and other similar technologies has been associated with the extension of e-commerce especially as consumers interact to extend a business transaction (Bocconcelli, et al., 2017; Jones, et al., 2015; McCann \& Barlow, 2015; Sarosa, 2012). Furthermore, a business transaction could come as a result of interactions of various components within, and outside the realm of an organisation. Researchers (Liebana-Cabanillas \& Alonso-Dos-Santos, 2017; Hajli, 2015) treat social commerce as a subset of e-commerce. Whereas e-commerce has relied on the website to complete a business transaction, s-commerce usually employs other channels agreed upon by its participating actors to complete the buying process (Liebana-Cabanillas \& Alonso-Dos-Santos, 2017). In a study to analyse use of SMN and patterns of behavior by SMEs in Portugal, Fernandes, et al. (2016) identified two types of social network use. These 
are: 1) product-client interaction and knowledge/research, and 2) market orientation. According to Bocconcelli, et al.(2017), SMN are a key resource in improving SMEs sales process thereby assisting SMEs to overcome their size-related limitations. In Indonesia, Sarosa (2012), has reported keen interest by some SMEs to incorporate SMN to improve their business operations. This study aims to explain this social-technical innovation and the e-commerce process that incorporated Facebook as a tool for reaching new markets.

Extant literature (Alsaad, et al., 2017; Liebana-Cabanillas \& Alonso-Dos-Santos, 2017; Hajli, 2015; Gefen, et al., 2003) has postulated the role of trust in e-commerce decisions to buy. Trust comprises two main dimensions: cognitive and behavioural (Liebana-Cabanillas \& Alonso-Dos-Santos, 2017). According to Gefen, et al. (2003), online trust is built through the following: 1) a belief that the vendor has nothing to gain through cheating, 2) a belief that there are safety mechanisms built into the web site, 3) by having a typical interface, and 4) one that is easy to use. This study aims to explore the role of trust in the context of SME websites and a consideration of other organisational and environmental factors in the application of business to consumers (B2C) in a developing country. Furthermore, Gefen, et al.(2003) argue that trust is a social antecedent, whereas other notable TAM variables such as perceived ease of use and perceived usefulness are technological antecedents. There is a likely chance that social-technical interaction can take place through the web platform and the characteristic of trust to actualise an e-commerce entrepreneurial process, drawing from Avgerou \& Boyi (2013). This study aims to investigate these phenomena by enacting an SME e-commerce environment in the Botswana context. Table II presents a summary of the factors enabling and inhibiting e-commerce adoption in SMEs.

Table II $<<$ Insert here $>>$ 
Table II: Factors enabling and inhibiting e-commerce adoption in SMEs

\subsection{Previous Theories of E-commerce Adoption Research}

Previous studies have employed various theories to study e-commerce adoption in SMEs. The most common and popular ones are the Theory of Planned Behaviour (TPB), the Technology Acceptance Model (TAM), the Technology-Organisation-Environment (TOE) framework, the Perceived E-readiness Model (PERM), and the Diffusion of Innovation Theory (DIT). As argued by previous studies (Kabanda \& Brown, 2017; Shemi \& Procter, 2013; Gefen, et al., 2003), most theories have paid more focus on technology, and so are unable to reveal the social-technical nature of e-commerce adoption in SMEs.

The next section tackles Contextualism theory proposed by the theoretical framework of this study.

\subsection{The Theoretical Framework for this Study-Contextualism in E-commerce}

The theory of Contextualism was proposed by Pettigrew (1987, 1990, and 1997) in his studies on organisations and change, which outline three components that concern human action at the organization level: these are content, context and process. Pettigrew (1990, p. 
268) explained that 'theoretically sound and practically useful research on change should explore the content, contexts, and process of change together with their interconnections through time.' Furthermore, he argues that there must be explicit acceptance that change in organisations is multifaceted; 'involving political, cultural, incremental, environmental, and structural, as well as rational dimensions' (p. 268). Early studies on Contextualism theory in information systems (IS) have been applied by Walsham and Waema (1994) in studies on Information systems strategy change in organisations, and Walsham and Sahay (1999) IS public administration. They defined Content as the intended IS drawn on in process and can be viewed as an aspect of planned changes to products and services, business processes, organizational structures and roles/cultural and political attitudes. Context was defined as the outer and inner issues relating to IS at different levels in the organization, and the broader organizational, sectoral and national IS contexts, IS social relations, the infrastructure and history. Process is defined as the 'Interconnectedness of events and actions over time. This includes cultural as well as political perspectives (Walsham and Waema, 1994, p.156).

E-commerce adoption, which is an aspect of IS, is viewed as a process of change in this study, assisting the firm to alter the processes of negotiation, buying, selling, investing and banking through e-mail, Internet, the application of the Website and Facebook interaction. Such a process may be influenced by various actors and actions, structures and roles, cultures and managerial inclinations that are influenced from internal and external conditions of ecommerce. Drawing from Walsham and Waema's (1994) IS Contextual framework, specific areas of consideration for e-commerce adoption using SMN have been developed from this study as shown in Figure 1.

Figure $1<<$ Insert here $>>$ 
Content issues of e-commerce using SMN represent what the firm intends to use, as defined by managers, including the structure and roles; Context defines how the internal and external environment have been described and articulated; and Process defines the cultural and power interpretation of e-commerce using SMN in the firm. It must be noted, borrowing from Walsham and Waema (1994, p.156), that 'although elements of the various components have been identified separately for analytical purposes, they are invariably interconnected in practice.

A particular benefit for drawing from this framework in the interpretive paradigm is in cognizance of the realisation of the various social relations, mechanisms and forces operating at different levels of the organisations and across the various units of the firm. This is supported by Pettigrew (1997, p.338) who described a process as 'a sequence of individual and collective events, actions and activities unfolding over time in context'. It is also naturally understood that the enactment of the e-commerce process in the organisation draws from the characteristic of e-commerce that embodies social processes (Shemi, 2013). Therefore, "it is too narrow to see change just as a rational and linear problem-solving process... explanations of change have to be able to deal with continuity and change, actions and structures, endogenous and exogenous factors, as well as the role of chance and surprise" ( Pettigrew, 1987, p. 658).

The framework will be employed as a meta-framework in the interpretive paradigm to provide a theoretical lens in the understanding of e-commerce adoption changes in the firm. Hence, an inductive case research will be followed to trace social processes that affect and are affected by e-commerce actions and structure, roles and culture in the firm. As argued by 
Walsham and Waema (1994, p.156), it is imperative that the researcher 'does not place too great an emphasis on fitting the data to the framework, rather than seeking to interpret events and actions as encountered' in the case.

\section{Research Methodology}

\subsection{The Research Approach and Design}

This study followed an interpretive tradition (Walsham, 2006; Shemi, 2013) as a main paradigm to answer the research questions in an in-depth manner. An interpretive, qualitative case study was chosen as a means of unearthing detailed issues that shape the conceptualization and development of e-commerce in a natural setting. Amongst the pool of SMEs that were identified to be developing e-commerce and had agreed to participate in the study, myBot (a pseudo-name), was selected and an appointment was scheduled with the general manager, pseudo-named Lerato for purposes of anonymity. Semi-structured face-toface interviews and unstructured interviews were employed as the main method of inquiry. The researcher, who is the author of this article, explained the purpose of the study and how the engagement with the firm would be carried out. Interviews were scheduled for $30 \mathrm{~min}$ to an hour and took place over a span of 8 weeks from September 2010 to December 2011. Web-site content analyses, and observation of the working environment, were also employed at the close of the interview process.

As with the interpretive (Walsham, 2006) norm, the researcher employed a subjective inquirer role that oscillated between close engagement (Nandhakumar and Jones, 1997) to understand the various roles and decisions taken by the manager for initiating and improving e-commerce adoption, and withdrawing at certain instances to undertake reflection on the issues that had been gathered from the interviews. Care was taken to avoid pushing for ecommerce opinions that were well-known elsewhere, a culture that largely aligns with objectivism, which is a positivist trait (Kabanda \& Brown, 2017; Shemi, 2013).

\subsection{Data Collection and Data Analysis}

Data collection and data analysis overlapped, to allow early analysis (Miles and Huberman, 1994). Semi-structured and unstructured face-to-face interviews formed the main methods of interacting with the firm. Five face-to-face interview sessions were carried out with the manager of myBot in two phases of the fieldwork period, at the organisation's premises. A sample of the questions that were developed, after the review of literature, was sent in advance to allow the interviewee to be familiar with the research questions. The questions 
were asked in an interactive manner to allow the manager to describe various issues. Interviews were either taped or phone-recorded and later summarized for further analysis. Short notes were written as the interviewee answered the questions which were later read to the interviewee before leaving the premises.

The first category of questions focused on the nature and background of the organisation: the size, location, number of employees, the type of ICT being used and on what activities, the type of Internet connection, whether the organisation had a website, the mobile devices used for communication, reasons for developing these services, and the reasons why, if they did not apply. Issues that related to the mission and business objectives, culture, and structure, were probed as well as the educational background of the manager, their interest in growing the business and where they were leading the firm.

The second category of questions related more to the use of Internet, e-mail and web technologies, mobile devices and the extent of their use. In linking up with the first set of questions, the research was interested in knowing the relationship between the business objectives and myBot's Internet applications. This would build up to questions that related to benefits and challenges of using Internet, web technology, and other applications where possible. The researcher also interacted with the interviewee (Lerato) in such a way that there was one level of understanding of what e-commerce is, without making her feel uncomfortable or uneasy. This level of investigation naturally evolved into the third category of questions. The third category of questions focused on the challenges that myBot was facing in using Internet; web technology; any other ICTs they were using, and any challenges they were facing; and what efforts if any, were being employed to overcome the said challenges.

\section{Results}

Given the framework of Contextualism in Figure 1 that was discussed earlier, this section provides the constituent areas that interacted over time to give a picture of myBot's position relating to e-commerce entrepreneurship. Thus the resultant position of the firm is a reflexive outcome of interactions of key components such as organisational characteristics, the structure and role; Web application; Facebook and e-mail applications; managerial perception and intentions to innovate using Facebook, and the local business conditions that facilitated or limited the process of e-commerce entrepreneurship. 


\subsection{Aspects of Content and Context on the Nature, Vision and history of myBot}

The small firm, myBot, was established in 1970 by one of the key public firms in Botswana with a purpose of developing the rural-based handicraft industry. The main objective and vision was to assist rural Botswana women to find market for their basketry and other handicrafts, and thereby provide a source of income for their sustenance. Another purpose was to showcase Botswana's agricultural and tourism history that was portrayed in the art and craft materials. However, sales could not improve significantly. In 1993, myBot became a private organisation and the firm improved its direct marketing and innovation strategy by targeting the buyers and sellers throughout the Southern African region and beyond. MyBot became influential in assisting rural women weavers in the formation of business groups. In addition, myBot assisted in publishing images about each weaver beside their product on their website.

In 2002, the firm was bought by the current management team. Over 80 percent of myBot's turnover comes from selling handmade crafts, and it has now become the largest exporter of arts and crafts products in Botswana. At the time of the field work, there were thirty-five employees that assisted in executing myBot's business mandate.

\subsection{Aspects of Context on Business Characteristics of myBot}

The business was mainly focused on the shop at the beginning, showcasing various traditional products but in recent years, myBot has expanded to two more units, a restaurant and conference centre. The restaurant also provides traditional meals that can be served to visitors. Most of the buyers of myBot's handicrafts buy the products from the shop. The government of Botswana is the biggest buyer, followed by some private firms and a smaller portion comes from individual tourists who visit the firm and those who buy online, mainly from the United States of America.

Adding to the uniqueness of their products, myBot claims to contribute to preserving Botswana culture by maintaining a gallery that showcases the local women weavers who are the designers of most of the baskets and artwork being sold in the shop. For ethical purposes and to protect the privacy of individual weavers, the artwork has not been disclosed. The gallery also stocks some products that are sourced from neighbouring countries such as South Africa, Namibia, Zimbabwe and others. Another business facility at myBot is a restaurant facility that provides traditional and exotic meals to the public especially those that visit the shop. The conference centre facility was another option for generating income for myBot. 
Some traditional activities such as music shows are also held to raise awareness and educate the public about the history of Botswana.

\subsection{Aspects of Context in Use of ICTs, Web-based Applications and Social Media Networks}

There is no computer department at myBot and most workers are illiterate in the use and appropriation of computers. Of the three departments operating at myBot, the use of computers is mainly in the shop; assisting with the point of sale system. This, however, is not connected to Internet. A Disk Operating System had been used to facilitate their point of sale system operations. However, this is too old and not compartible with most modern operating systems such as Windows. It was not possible to retrieve sales information using the old storage devices. The delay in changing over, according to Lerato, has been due to:

'lack of finance and specialised ICT personnel who can implement this change for us.'

myBot began online business around the year 1999. The reason for developing the website was to meet the needs of the foreign tourists who were unable to travel to Botswana but could access information about traditional Botswana artifacts on the Internet. The company has a local presence (.bw) through a Botswana Internet Service Provider (ISP). An international .com presence had been in existence in USA until late 2010 when this option ceased. Thus they hosted their web domain through a local presence (.bw). Lerato explained that before the global economic recession in 2008 and 2009, business transactions generated through myBot's website accounted for $30 \%$ of all company sales, but she stated that the sales dropped tremendously and that they had now started to improve as follows;

'after the recession, sales dropped to less than 5\% and sometimes even lesser but this has started to improve again. We now have up to $10 \%$ of sales generated through the website.'

myBot has advertised some of the arts and crafts products. The online store shows some of the items that are displayed in the gallery, such as basketry, with prices indicated alongside each item. Further, it provides information for viewers who want to proceed to make a purchase. Other than the baskets and bowls that are marketed on myBot's website, there are also San crafts, also known as Bushman crafts. There are also books and various traditional items on Botswana culture and its history, being marketed on myBot's website. These items could also be purchased physically from the shop. 
Customers accessing myBot's website can view some of the products and may opt to complete the business transaction through email and later pay through normal banking methods such as electronic funds transfer (EFT) or by credit card. The purchased item is later dispatched by express courier to the buyer. Still then, Lerato would like to assure her clients of the social element of trust that can be embedded in the online transaction, as she explained:

'The experience of my boss some years back is that people like the individual touch, they would like to be able to communicate, get to know you slightly in a way, rather than just staying on the website, filling in an order form....

All our orders that we've had so far, have results from e-mails that I can quote. Well, there's an option that they can click on the website if they want ten of these, or whatever number they choose, but they don't do that...

So even people who are re-ordering, they would rather email first, chat a bit and then go to place an order. I guess they are a bit hesitant because they don't know Botswana that well, and if they do, possibly they may not know myBot.'

Some information was also obtained regarding the yearly turnover of exports at myBot. Figure 2 shows a sharp decline in export sales for the period 2007 to 2011 due to the global recession that began in 2008. The results for 2011 did not include the month of November and December, 2011, hence the low figures.

Figure 2: $<<$ Insert here $>>$ 
myBot had started marketing its products on Facebook and Lerato noted that other markets such as Japan, the UK and rest of Europe had started to respond by sending inquiries. The manager suspected that the influx of mails could have been due to the new channel of social networking using Facebook.

A website content analysis based on 13 characteristics of an e-commerce website as suggested by Choudhury \& Choudhury (2010) shows the following in Table III. A tick ( $\sqrt{ }$ ) indicates the presence of a feature on the website and a blank indicates the absence of a feature.

Table III $<<$ insert here $>>$ 
There are no payment features on myBot's website as payment as shown in Table III. myBot. There are no visitor statistics being captured through myBot's website.

Interactivity through social media network was implemented through Facebook and enabled repeat buying once the consumer returned to the United States of America (USA). Lerato confirmed that all e-commerce transactions using Facebook, and sometimes in conjunction with her mobile phone were repeat transactions and no new clients had been engaged as first time buyer solely through the web site information. The type of e-commerce being represented above is mainly $\mathrm{B} 2 \mathrm{C}$, with s-commerce or mobile commerce being the defining norm through Facebook interactions.

\subsection{Aspects of Context and Process in Manager's Perception and Entrepreneurial choices for E-commerce}

The manager's perception and attitude provide the direction for e-commerce appropriation at myBot. These are key elements that can impact positively or negatively in the adoption of ecommerce at myBot. Lerato explained the managing director's position, by saying that:

'My boss is very enthusiastic about Internet and what it can do for myBot. He's very keen to try out and discover new ICT innovations.'

At the organisational level, Lerato's educational background adds a positive dimension to the management of myBot, giving it a strategic direction in the application of Internet and ecommerce entrepreneurship. There was evidence of enthusiasm in the knowledge and utilisation of email, Internet, and social media applications that can boost myBot's business outlook. However, such enthusiasm was somewhat lacking among other staff in the organisation. 


\subsection{Aspects of Context and Process in Factors Affecting E-commerce Adoption using $S M N$}

Several contextual factors seem to interact to influence myBot's ability to use web applications and Facebook commerce. Lerato explained the need to develop e-commerce in the firm but lamented the lack of skilled ICT personnel, as she stated;

'myBot has a desire to further develop its e-commerce offerings but at the moment it is difficult as there is no one person dedicated for this task'.

At the beginning of fieldwork in September 2010, the only products that were displayed on myBot's website were baskets but later in the year, other products were included such as San crafts, books about Botswana culture and music CD's. Lerato had explained that time was a key factor in the development of e-commerce as she had to take up this role besides other responsibilities of managing the business. Another constraint that Lerato lamented about was the slow speed of the Internet. In one of the interviews, she explained that:

'Internet speed is still very slow and the cost of maintaining Internet is high for us.'

She later disclosed that on average, the annual rate was about Botswana Pula 2000 (slightly less than US \$200). A key challenge for the development of e-commerce at myBot is how to meet the salary demands of skilled ICT personnel who could focus on further website improvements. Thus she hoped for improvement in the business sales so that e-commerce issues could pay for an additional staff with ICT expertise. Further, the lack of funding for ecommerce projects was another factor impeding website improvement for myBot. It was not the intention of management to seek other sources of finance. This aspect appears to be exerting the power that top management had in driving e-commerce using SMN.

The results show that there are more significant organisational factors that drive ecommerce adoption than factors that hinder it at myBot. With regard to context at myBot, management had decided to interact with buyers as a way of trying out how Facebook worked. It was learnt that online consumers were repeat buyers, those that had physically visited the firm in Botswana. They then would return home and place orders through the website using the identified codes. Once the consumer was satisfied of a safe transaction, they then place orders through e-mail but with reference to items that existed on the website. Lerato explained that she would personally follow up the orders with telephone calls to verify 
the validity of the sender and the order details. Cash payments are facilitated through credit card by traditional banking methods or electronic funds transfer.

The factor of trust can be seen to be enacted through s-commerce, confirming Hajli, (2015) and Avgerou \& Boyi's (2013) work in China, where online trust was assisted through physical verification. This implies that security concerns are still considered critical in the ecommerce environment described above.

\section{Discussion of Findings}

This section is presented with respect to the research questions as follows:

\subsection{How do SMEs incorporate social media networks in e-commerce adoption and entrepreneurship?}

The manager's innovativeness and ability to link with previous clients gave myBot a push to realise the potential of Facebook. This can be drawn from the culture and power aspects that are defined in Contextualism theory. Operating from a scenario where resources for updating the operating system, and other requisite ICT applications are either limited or of low quality, myBot has been able to capitalise on the ease of doing business using Facebook.

E-commerce adoption and entrepreneurship using Facebook are modelled through a social environment enabled by trust. This is a unique feature that the organisation has pursued and can create a long-lasting economic relationship between myBot and its global clients in the US. The findings of this study have illustrated the significance of Facebook in advancing e-commerce adoption at myBot. This corroborates previous studies (Bocconcelli, et al. 2017, Fernandes, et al., 2016; McCann \& Barlow, 2015; Dahnil, et al, 2014), that found that SMN such as Facebook have a significant role to play in SME e-commerce development. This is done in conjuction with other tools such as the Internet and e-mail, wherever possible. The findings are partly similar to Kabanda \& Brown's (2017) research in Tanzanian SMEs which noted the inclination towards cultural bargaining systems such as face-to-face, and a limited use of website applications for e-commerce adoption. However, there's some contrast as Facebook discussion continued to enforce trust before payments could be made through the bank. It must be mentioned as well that all credit card purchases were completed by persons that had first visited the shop.

The finding at myBot corroborates the study by Fernandes, et al.(2016) especially in the market orientation aspect. In this case the niche market in the USA provides an extension of e-commerce entrepreneurship. Furthermore, there is similarity with Avgerou \& Li's (2013) work in China which demonstrated how social networks can be enacted with web technology 
to achieve an economic gain for the firm. However, the role of the web-site at myBot is still of a limited nature, except that of advertising its products.

In terms of the limitation of the website application, the findings are consistent with previous findings by Ramayah, et al.(2016) in Malaysia, Kabanda \& Brown (2017) in Tanzania, and early research findings by Molla \& Licker (2005) in South Africa and (Lefebvre, et al., 2005) in Canada.

\subsection{What factors influence e-commerce adoption using social media networks?}

The manager's innovativeness and commitment are key factors that stand out in this case. Unlike the findings of other studies in previous literature where SME managers were relaxed, lacked ICT knowledge for innovating e-commerce adoption (Kabanda \& Brown, 2017; Alyoubi, 2015; Molla \& Licker, 2005), the manager at myBot showed keen interest to improve her firm's entrepreneurial position by personally seeking better ways of establishing linkages with visitors to the shop. The manager has been enthusiastic and optimistic to develop business relationships using Facebook beyond what is normal in the Botswana context. These results corroborate results revealed by (Ghobakhloo \& Tang, 2013 and (Ghobakhloo, et al., 2011).

Another key factor is trust as envisaged in the completion of the buying process. Trust can be seen to be enacted between two parties; the manager Lerato on myBot's side and the global consumers. This aligns with Liebana-Cabanillas \& Alonso-Dos-Santos (2017) characteritics of trust, that of being cognitive and behavioural. The physical visitation of the buyers enabled them to establish trust which they depended on when making repeat orders. The findings align with previous findings (Alsaad, et al., 2017; Bocconcelli, et al., 2017) that enphasise the significance of trust in e-commerce adoption process using SMN.

\subsection{Reflection on Contextualisation - Figure 1}

Going a little further, it is imperative to borrow from the thought of Pettigrew (1997) who argued that Contextualism is a 'natural way' of embracing change in organisations. However, change using SMN such as Facebook, for example, may not necessarily be the same for every organisation. Each organisation has their own understanding, definition and as well as interpretation of content, context and process that should reflect how SMN are applied. It is practically impossible to predict the results, much as others may want to. Furthermore, the application of the framework in Figure 1 may not be applied word for word or phrase by phrase as argued by Walsham (2006), rather the framework is a kind of a guide to 
understanding e-commerce entrepreneurship in one small Botswana firm. Results of the study and the application of Figure 1 have been summarised in Table IV.

\section{Conclusion}

This study has explained how an SME, pseudo-named myBot in a developing country has incorporated SMN in e-commerce adoption and entrepreneurship process. The research was undertaken using a qualitative and interpretive approach that involved close interaction with the SME manager to reveal contextual and social issues that affected the e-commerce development process. Primarily, social commerce using Facebook is the main types of ecommerce that ensued between the consumers in USA and myBot. The main factors are trust between the participating actors, the manager's commitment and innovativeness. 
The application of Contextualism assisted in providing a theoretical lens for understanding the e-commerce entrepreneurship process as well as placing an emphasis of the practical application in an SME context. This paper makes a theoretical contribution to literature on e-commerce using social commerce in African SME contexts. The use of theory to provide an understanding of SMEs is another value provided from this study. The paper discusses and applied Contextualism theory (Pettigrew, 1990) to assist in exploring the nature of SME environment for e-commerce development using SMN.

Future research could look into other social media networks such as Whatsapp, Twitter, Youtube, Myspace and other tools, and how they contribute to e-commerce entrepreneurship in resource-constrained SME environment in other industries, and regions of the world. Comparative studies on SMN are also possible. In terms of future implications, further studies could involve other global consumers to obtain a complete picture of online trust in the application of SMNs such as Whatsapp, Twitter, Linkedin, and other popular SMN. Other studies could investigate social processes that enable s-commerce.

The presentation of this study has some limitations. The revelation of this study may have changed due to the dynamic changes in the ICT industry and how these are employed in Botswana. Thus, results may not be generalized to other contexts. The study has a methodological limitation as it only had one informant as per the nature of the SME. Further work is needed to establish the nature of e-commerce entrepreneurship in firms that employ other mobile devices and SMN applications, and have a wider reach of global consumers. The application of theory in this study inclined towards interpretive and qualitative analysis, which may not be a familiar domain for most readers.

\section{References}

Abou-Shouk, M. A., Lim, W. M. and Megicks, P. (2016), "Using competing models to evaluate the role of environmental pressures in ecommerce adoption by small and medium sized travel agents in a developing country", Tourism Management, Vol. 52, pp. 327-339.

Ahmedova, S. (2015), "Factors for Increasing the Competitiveness of Small and MediumSized Enterprises (SMEs) in Bulgaria", Procedia-Social and Behavioral Sciences, Vol. 195, pp. 1104-1112.

Al-Bakri, A. A. and Katsioloudes, M. I.(2015), "The factors affecting e-commerce adoption by Jordanian SMEs", Management Research Review", Vol. 38 No. 7, pp. 726-749. 
Alsaad, A., Mohammad, R. and Ismail, N. A.(2017), "The moderating role of trust in business to business electronic commerce (B2B EC) adoption", Computers in Human Behavior, Vol. 68, pp. 157-169.

Alyoubi, A. (2015), "E-commerce in Developing Countries and How to Develop Them During the Introduction of Modern Systems", Procedia Computer Science, Vol. 65, pp. 479-483.

Avgerou, C. (2001), "The significance of context in information systems and organisation change", Information Systems Journal, Vol. 11, pp. 43-63.

Avgerou, C. and Boyi, L. (2013), "Relational and institutional embeddedness of Web-enabled entrepreneurial networks: case studies of netrepreneurs in China", Information Systems Journal, Vol. 23 No 4, pp. 329-350.

Awa, H. O., Ojiabo, O. U. and Emecheta, B. C. (2015), "Integrating TAM, TPB and TOE frameworks and expanding their characteristic constructs for e-commerce adoption by SMEs", Journal of Science \& Technology Policy Management, Vol. 6 No 1, pp. 76-94.

Baller, S., Dutta, S. and Lanvin, B. (2016), The Global Information Technology Report 2016: Innovating in the Digital Economy, Insead, World Economic Forum.

Bocconcelli, R., Cioppi, M. and Pagano, A. (2017), "Social media as a resource in SMEs' sales process", Journal of Business \& Industrial Marketing, Vol. 32 No 5, doi: 10.1108/JBIM-11-2014-0244

Botswana Ministry of Commerce and Industry (1999). "Policy on Small, Medium, and Micro Enterprises in Botswana", Issue 1, Government Paper.

Cragg, P., Caldeira, M. and Ward, J. (2011), "Organisational Information Systems Competencies in small and medium-size enterprises", Information \& Management, Vol. 48, pp. 353-363.

Dahnil, M. I., Marzuki, K. M., Langgat, J. and Fabeil, N. F. (2014,) "Factors Influencing SMEs Adoption of Social Media Marketing", Procedia-Social and Behavioral Sciences, Vol. 148, pp. 119-126.

Daniel, E. (2003), "Exploration of the inside-out model: e-commerce integration in SMEs", Journal of Small Business and Enterprise Development, Vol.10 No 3, pp. 233-249.

Eijdenberg, E. L., Paas, L. and Masure, E.(2015), "Entrepreneurial motivation and small business growth in Rwanda", Journal of Entrepreneurship in Emerging Economies, Vol 7 No 3, pp. 212-240. 
Fernandes, S., Belo, A. and Castela, G.(2016), "Social network enterprise behaviours and patterns in SMEs: Lessons from a Portuguese local community centred around tourism industry", Technology in Society, Vol. 44, pp. 15-22.

Gefen, D., Karahanna, E. and Straub, D. W. (2003), "Trust and TAM in online shopping: An integrated model", MIS Quarterly, Vol. 27 No. 1, pp. 51.

Ghobakhloo, M., Aranda, A. D. and Amado, B. J. (2011), "Adoption of e-commerce applications in SMEs", Industrial Management \& Data Systems, Vol. 111 No 8, pp. pp.1238-1269.

Ghobakhloo, M. and Tang, S. H.(2013), "The role of owner/manager in adoption of electronic commerce in small businesses The case of developing countries", Journal of Small Business and Enterprise Development, Vol. 20 No 4 , pp. 754-787.

Grandon, E. E., Nasco, S. A. and Mykytyn, P. P. (2011), "Comparing Theories to Explain Ecommerce Adoption", Journal Of Business Research, Vol. 64 No 3, pp. 292-298.

Grant, K., Edgar, D., Sukumar, A. and Meyer, M. (2014), "'Risky Business': Perceptions of E-business Risk by UK small and medium enterprises (SMEs)", International Journal of Information Management, Vol. 34, pp. 99-122.

Hajli, N. (2015), "Social Commerce Constructs and Consumer's Intention to Buy", International Journal of Information Management, Vol. 35 No 2, pp. 183-191.

ITU -"ICT Statistics Botswana". International Telecommunication Union. http://www.itu.int/ITU-D/icteye/DisplayCountry.aspx?code=BWA accessed 28/10/2017

IWS - "Botswana Internet Usage and Marketing Report". Internet World Stats. http://www.internetworldstats.com/af/bw.htm, accessed 28/10/2017.

Jahanshahi, A. A., Zhang, S. X. and Brem, A. (2013), "E-commerce for SMEs-empirical insights from three countries", Journal of Small Business and Enterprise Development, Vol. 20 No 4, pp. 849-865.

Jarvenpaa, S. L. and Leidner, D. E. (1998), "An information company in Mexico: Extending the Resource-Based View of the Firm to a Developing Country Context", Information Systems Research, Vol. 9 No 4, pp. 342-361.

Jones, N., Borgman, R. and Ulusoy, E. (2015), "Impact of social media on small businesses", Journal of Small Business and Enterprise Development, Vol. 22 No 4, pp. 611-632.

Jones, P. and Beynon, D. (2011), "ICT impact within the SME sector: Guest EditorialJournal of Systems and Information Technology, Vol. 13 No 2. 
Kabanda, S. and Brown, I. (2017), "A Structuration Analysis of Small and Medium Enterprise (SME) Adoption of E-commerce: The Case of Tanzania", Telematics and Informatics, Vol. 34, pp. 118-132.

Kabongo, J. D. and Okpara, J. O. (2014), "ICT possession among Congolese SMEs: an exploratory study", Journal of Small Business and Enterprise Development, Vol. 21 No 2, pp. 313-326.

Kapurubandara, M. (2009), "A framework to e-Transform SMEs in developing countries", Electronic Journal of Information Systems in Developing Countries, Vol. 39 No 3, pp. 124.

Karyda, M., Kiountouzisa,E., Kokolakis, S.(2005), " Information systems security policies: a contextual perspective", Computers \& Security, Vol 24, pp. 246-260

Kurnia, S., Choudrie, J., Mahbubur, R. M. and Alzougool, B. (2015), "E-commerce technology adoption: A malaysian grocery SME retail sector study", Journal of Business Research, Vol. 68, pp. 1906-1918.

Lefebvre, L. A., Lefebvre, E., Elia, E. and Boeck, H. (2005), "Exploring B-to-B e-commerce adoption trajectories in manufacturing SMEs", Technovation, Vol. 25, pp. 1443-1456.

Liang, T. and Turban, E. (2011), "Introduction to the special issues social commerce: A Research Framework For Social Commerce", International Journal of Electronic Commerce, Vol. 16 No 2, pp. 5-14.

Liebana-Cabanillas, F. and Alonso-Dos-Santos, M. (2017), "Factors that Determine the Adoption of Facebook Commerce: The Moderating Effect of Age", Journal Of Engineering and Technology Management, Vol. 44, pp. 1-18.

Marcelo, P., João, T., Lisboa, V. and Yasin, M. M. (2014), "E-commerce strategies and corporate performance: an empirical investigation", Competitiveness Review, Vol. 24 No 5, pp. 463-481.

McCann, M. and Barlow, A. (2015), "Use and measurement of social media for SMEs", Journal of Small Business and Enterprise Development, Vol. 22 No 2, pp. 273-287.

MCST, 2007. NICT Policy, Ministry of Communication Science and Technology, Botswana Government, Gaborone.

Miles, M. B. and Huberman, A. M. (1994), Qualitative Data Analysis: A source book of new methods. 2nd ed. Beverly Hills: Sage Publications.

Mohammed, Z. A. and Tejay, G. P. (2017), "Examining privacy concerns and ecommerce adoption in developing countries: The impact of culture in shaping individuals' perceptions toward technology", Computers \& Security, Vol. 67, pp. 254-265. 
Molla, A. and Heeks, R. (2007), "Exploring E-Commerce Benefits for Businesses in a Developing Country", The Information Society, Vol. 23 No 2, pp. 95-108.

Molla, A. and Licker, P. S. (2005), "Perceived E-Readiness Factors in E-Commerce Adoption: An Empirical Investigation in a Developing Country. International Journal of Electronic Commerce, Vol. 10 No 1, pp. 83-110.

Moursund, D (2005). Introduction to Information and Communication Technology in Education. Eugene.

Nandhakumar, M. and Jones, M. (1997), "Too close for Comfort? Distance and Engagement in interpretive information systems research", Information Systems Research, Vol. 7, pp. 109-131.

Olatokun, W., and Kebonye, M. (2010), "E-commerce Technology Adoption in Botswana", International Journal of Emerging Technology and Society, Vol. 8 No 1, pp. 42-56.

Parker, C. M. and Castleman, T. (2009), "Small firm e-business adoption: a critical analysis of theory", Journal of Enterprise Information Management, Vol. 1 No 1, pp. 167-182.

Pettigrew, A. (1987), " Context and Action in the Transformation of the Firm ", Journal of Management Studies, Vol. 24 No 6, pp. 649-670.

Pettigrew, A. (1990), "Longitudinal field research on change: theory and practice", Organisation Science, Vol. 1 No 3, pp. 67-292.

Pettigrew, A. (1997), “What is a Processual Analysis?” Scandinavian Journal of Management Studies", Vol. 13, No. 4, pp. 331-503.

Pickernell, D., Jones, P., Packham, G., Thomas, B., White, G. and Willis, R. (2013), "Ecommerce trading activity and the SME sector: an FSB perspective", Journal of Small Business and Enterprise Development, Vol. 20 No 4, pp. 866-888.

Rahayu, R. and Day, J. (2015), "Determinant Factors of E-commerce Adoption by SMEs in Developing Country: Evidence from Indonesia", Procedia-Social and Behavioral Sciences, Vol. 195, pp. 142-150.

Ramayah, T., Ling, N. S., Taghizadeh, S. K. and Rahman, S. A. (2016). Factors influencing SMEs website continuance intention in Malaysia", Telematics and Informatics, Vol. 33, pp. $150-164$.

Sarosa,S. (2012), "Adoption of social media networks by Indonesian SME: A case study", Procedia Economics and Finance, Vol. 4, pp. 244-254.

Savrul, M., Incekara, A. and Sener, S. (2014), "The Potential of E-commerce for SMEs in a Globalizing Business", Procedia - Social and Behavioral Sciences, Vol. 150, pp. 35-45. 
Scupola, A. (2009), "SMEs e-commerce adoption: perspectives from Denmark and Australia. Journal of Enterprise Information Management, Vol. 22 No 1, pp. 152-166.

Shemi, A. P. (2013), Factors Affecting E-commerce Adoption in Small and Medium Enterprises, Salford, UK: University of Salford.

Shemi, A. P. and Procter, C. (2013), "Explaining contextual factors affecting e-commerce adoption", International Journal of Management Practice, Vol. 6 No. 1, pp. 94-109.

Sin, K. Y., Osman, A., Salahuddin, S.N., Abdullah, S., Lim, Y.J., Sim, C.L. (2016), "Relative Advantage and Competitive Pressure towards Implementation of E-commerce: Overview of Small and Medium Enterprises (SMEs)", Procedia Economics and Finance, Vol. 35, pp. 434-443.

Tan, J., Tyler, K. and Manica, A. (2007), "Business-to-business adoption of e-Commerce in China", Information \& Management, Vol. 44, pp. 332-351.

Tan, K. S., Chong, S. C., Lin, B. and Eze, B. C. (2009), "Internet based ICT adoption; evidence from Malaysian SMEs", Industrial Management \& Data Systems, Vol. 109 No 2 , pp. 224-244.

Taylor, M. and Murphy, A. (2004), "SMEs and e-business", Journal of Small Business and Enterprise Development, Vol. 11 No 3, pp. 280-289.

Turban, E. et al. (2008), Electronic Commerce: A Managerial Perspective. Upper Saddle River, NJ, Pearson Prentice Hall.

Ueasangkomsate, P. (2015), "Adoption E-Commerce for Export Market of Small and Medium Enterprises in Thailand", Procedia - Social and Behavioral Sciences, Vol. 207, pp 111-120.

Uzoka, F. M. E., Seleka, G. G. and Shemi, A. (2007), "Behavioural influences on ecommerce adoption in a developing country context", Electronic Journal of Information Systems in Developing Countries, Vol. 31 No 4, pp. 1-15.

Walsham, G. (2006), "Doing interpretive research", European Journal of Information systems, Vol.15, pp. 320-330.

Walsham, G., and Sahay, S. (1999), "GIS for district level administration in India: Problems and Opportunities", MIS Quarterly, Vol. 23 No 1, pp. 39-66.

Walsham, G. and Waema, T.M., (1994), "Information Systems Strategy and Implementation: A Case Study of a Building Society", ACM Transactions on Information Systems, Vol. 12, No. 2, pp. 150-173.

Wilson, H., Daniel, E. and Davies, I. (2008), "The diffusion of e-commerce in UK SMEs", Journal of Marketing Management, Vol. 24 No 5-6, pp. 489-516. 
Woschke, T., Haase, H. and Kratzer, J. (2017), "Resource scarcity in SMEs: effects on incremental and radical innovations", Management Research Review, Vol. 40 No. 2, pp. $195-217$.

Zaeid, A. N. (2012), "Barriers to E-commerce Adoption in Egyptian SMEs", International Journal of Information Engineering and Electronic Business, Vol. 3, pp. 9-18. 
E-commerce and Entrepreneurship in SMEs: Case of myBot

Table I: Botswana Internet Statistics

\begin{tabular}{ccccc}
\hline YEAR & Users & Population & \% Pen. & Usage Source \\
\hline 2000 & 15,000 & $1,712,000$ & $0.30 \%$ & ITU \\
2002 & 50,000 & $1,874,610$ & $3.60 \%$ & ITU \\
2007 & 80,000 & $1,842,323$ & $4.30 \%$ & $\underline{\text { ITU }}$ \\
2008 & 100,000 & $1,952,048$ & $5.10 \%$ & $\underline{\text { ITU }}$ \\
2009 & 120,000 & $1,990,876$ & $6.00 \%$ & $\underline{\text { ITU }}$ \\
2015 & 620,000 & $2,182,719$ & $28.40 \%$ & $\underline{\text { IWS }}$ \\
\hline
\end{tabular}

Table II: Factors enabling and inhibiting e-commerce adoption in SMEs 
Table III: myBot's Web site Analysis

\begin{tabular}{lc}
\hline Feature & Evidence in the Case \\
\hline $\begin{array}{l}\text { Security } \\
\text { Appearance }\end{array}$ & Satisfactory \\
$\begin{array}{l}\text { Adequate information about products and } \\
\text { services, } \\
\text { Speed in downloading the pages }\end{array}$ & $\sqrt{ }$ \\
$\begin{array}{l}\text { Navigation friendly } \\
\text { Search option/Search engine, }\end{array}$ & $\sqrt{ }$ \\
$\begin{array}{l}\text { Hyperlinks to other information } \\
\text { Information on member facilities }\end{array}$ & $\sqrt{ }$ \\
History and profile of the company & $\sqrt{ }$ \\
$\begin{array}{l}\text { Ability to obtain information in limited } \\
\text { number of pages instead of browsing several } \\
\text { pages, }\end{array}$ & $\sqrt{ }$ \\
$\begin{array}{l}\text { Option for providing feedback from } \\
\text { customers } \\
\text { Visitor statistics }\end{array}$ & $\sqrt{ }$ \\
Availability of interactive online activities & \\
\hline
\end{tabular}


Table IV: Application of Results of Figure-1

\begin{tabular}{|c|c|c|}
\hline $\begin{array}{l}\text { Aspects of } \\
\text { Contextualism }\end{array}$ & Figure-1 & Application of results at myBot \\
\hline Content & $\begin{array}{l}\text { Organisational structure and roles as } \\
\text { interpretation of E-commerce using } \\
\text { Facebook; } \\
\text { Changes to the norms and attitudes, } \\
\text { existing work practices in using e- } \\
\text { commerce; } \\
\text { - Changes to hardware, software and } \\
\text { related technological infrastructure } \\
\text { used. }\end{array}$ & $\begin{array}{l}\text { Management structure is basic; the manager } \\
\text { takes on the role of ICT officer. Investigates } \\
\text { what's best for her firm and makes decision } \\
\text { for the best affordable option. } \\
\text { Slow speed of the Internet. } \\
\text { MyBot hardware and Software have not changed } \\
\text { much in years, except for the website } \\
\text { development which does not allow payment. }\end{array}$ \\
\hline Context & $\begin{array}{l}\text { Outer context: Economic, legal, } \\
\text { political, social, competitive and } \\
\text { sectoral factors that are found in the } \\
\text { environment of the organization for } \\
\text { defining and articulating e- } \\
\text { commerce using SMN } \\
\text { - Inner context: Managerial, } \\
\text { structural, political, social and } \\
\text { cultural elements within the } \\
\text { organisation for defining and } \\
\text { articulating e-commerce using SMN }\end{array}$ & $\begin{array}{l}\text { Lack of explicit laws on e-commerce for } \\
\text { Botswana SMEs } \\
\text { The financial position of firm does not permit } \\
\text { it to focus on IT experimentation. } \\
\text { High cost of maintaining Internet } \\
\text { Enthusiasm in the knowledge and utilisation of } \\
\text { email, Internet, and Facebook that can boost } \\
\text { myBot's business outlook. } \\
\text { There is no one person dedicated for this task. } \\
\text { No payment features on myBot's website. }\end{array}$ \\
\hline Process & $\begin{array}{l}\text { Cultural perspective: The } \\
\text { formulation and implementation of } \\
\text { e-commerce process on the existing } \\
\text { culture; The norms and rules and } \\
\text { have the potential to affect them, } \\
\text { therefore these processes can have } \\
\text { an impact on the social context. } \\
\text { - Power perspective: involved in the } \\
\text { formulation and implementation e- } \\
\text { commerce using SMN; policy } \\
\text { altering or reinforcing the context in } \\
\text { which they take place. }\end{array}$ & $\begin{array}{l}\text { Trust between the parties. } \\
\text { The Manager takes on full responsibility to } \\
\text { engage with prospecting buyers. } \\
\text { Transactions take place using traditional } \\
\text { banking. } \\
\text { Manager is committed to push for engagement } \\
\text { using e-commerce using Facebook; } \\
\text { This shows innovativeness as well. } \\
\text { Customers place orders through e-mail using } \\
\text { reference codes that exist on myBot's website. }\end{array}$ \\
\hline
\end{tabular}




\section{E-commerce and Entrepreneurship in SMEs: Case of myBot}

Figure 1: Aspects of Contextualism Framework for e-commerce entrepreneurship using SMN

(Developed in this study) 


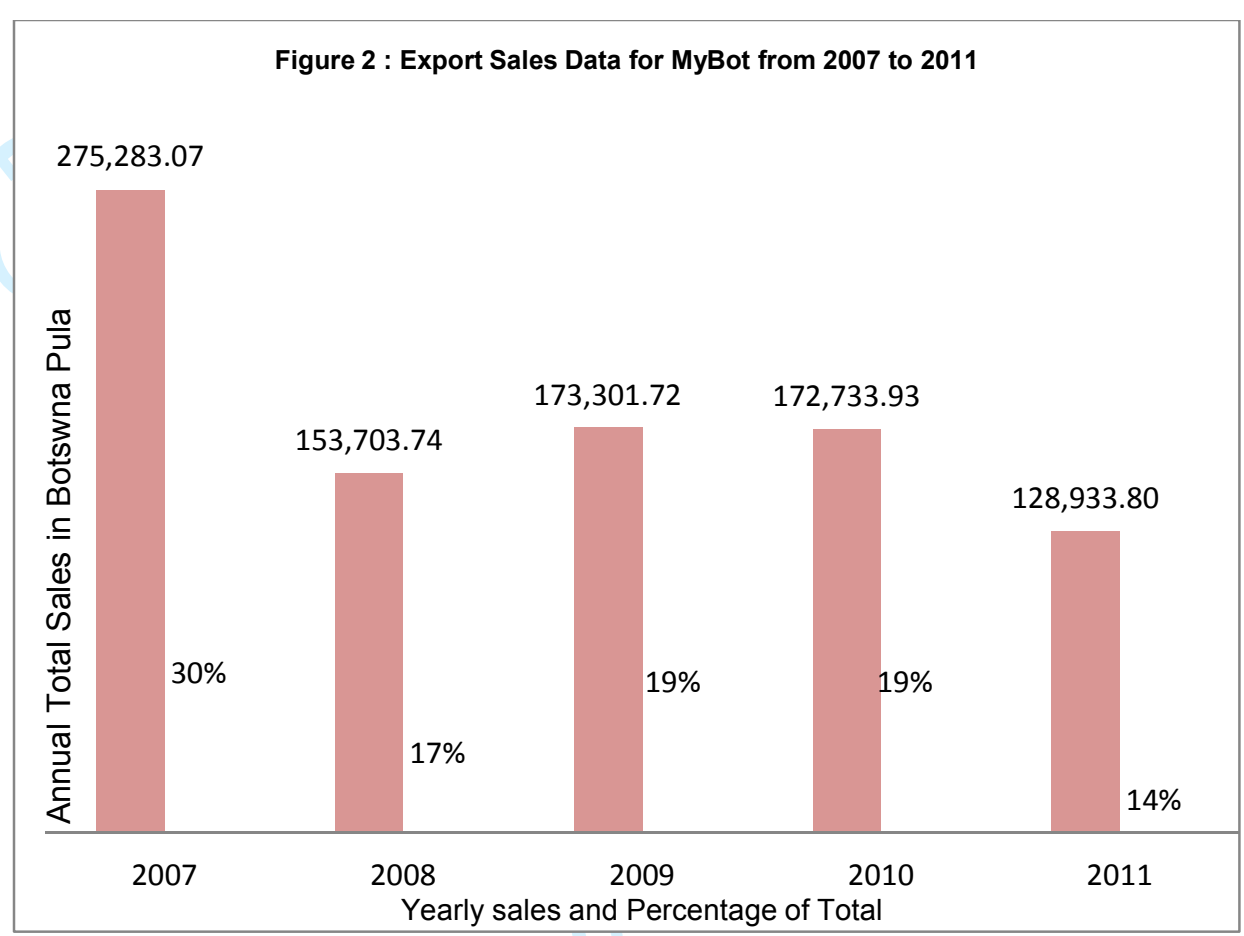

